\title{
Coexistence of spondyloarthritis and joint hypermobility syndrome: rare or unknown association?
}

\author{
J.B. Pinto Carneiro ${ }^{1}$, T. Pinto de Souza ${ }^{1}$, T.M.L. Antunes de Oliveira ${ }^{2}$, \\ S.L. Euzébio Ribeiro ${ }^{3}$ \\ ${ }^{1}$ Rheumatology Section, University Hospital Getúlio Vargas/Federal University of Amazonas, Brazil; \\ ${ }^{2}$ Regional Hospital of Taguatinga, Federal District, Brazil; \\ ${ }^{3}$ Rheumatology Department, Federal University of Amazonas, Brazil
}

\begin{abstract}
SUMMARY
We report two cases of siblings presenting coexisting non-radiographic axial spondyloartrhritis and joint hypermobility syndrome, complaining of back pain with morning stiffness, enthesitis, peripheral arthralgia, high erythrocyte sedimentation rate and C-reactive protein level and positive HLA-B27. The association of these two conditions is rare, but especially interesting in view of their contrasting features, one causing axial skeleton stiffness, the other a wider range of peripheral joint movements. Coexistence of these two opposite disorders causes confusion in diagnosis and management, resulting in lower quality of life for patients, as they are in pain from the early stages. Therefore, this association is suspected in young individuals with back pain and physical exam findings of peripheral joint hypermobility and axial skeleton loss of mobility.
\end{abstract}

Key words: Non-radiographic axial spondyloarthritis; Spondyloarthritis; HLA-B27; Hypermobility; Joint hypermobility syndrome.

Reumatismo, 2017; 69 (3): 126-130

Corresponding author Juliana Brandão Pinto Carneiro

Rheumatology Section

University Hospital Getúlio Vargas (HUGV)

Federal University of Amazonas (UFAM)

Av. Apurinã 04, Praça 14 de janeiro

CEP: 69.020.170, Manaus-AM, Brazil

E-mail: jubrandao@@hotmail.com

\section{INTRODUCTION}

he term non-radiographic axial spondyloarthritis (nrAxSpA) was created to designate patients suffering from early stages of ankylosing spondylitis (AS), which is a chronic inflammatory disease that affects the axial skeleton, peripheral joints and extra articular structures, characterized by sacroiliitis, enthesitis, uveitis, psoriasis, structural and functional impairments, causing low quality of life. It affects people younger than 45 years old with a ratio of roughly 2 to 1 in favor of males $(1,2)$. Strong familiarity of AS over three generations was demonstrated in a study and the molecule HLA B27, first described over 40 years ago, is the most important gene predisposing to axial spondyloarthritis (AxSpA). However, no consensus has been reached to date about the role of HLA B27 (1-3). The joint hypermobility syndrome (JHS) was first described in 1967 by Kirk et al. (4), who defined it as an increased range of movement of one or more joints seen in childhood, and declining in adulthood $(5,6)$. It is more frequently found in women and more prevalent among people of Asian and African descent, compared to Caucasians $(6,7)$. Also known as benign joint hypermobility syndrome (BJHS), this condition requires a clinical diagnosis that is carried out according to Brighton criteria, which include generalized joint hypermobility, resulting in recurrent joint dislocation, chronic limb and joint pain and skin involvement (8). Type III EhlersDanlos syndrome (EDS) is characterized by joint hypermobility, lax skin, a hereditary family pattern and may be associated with dysautonomia and fatigue (5). Some authors consider BJHS and EDS as synonyms $(8,9)$.

The coexistence of SpA and JHS is rare, with few reports in the literature, evidencing how difficult diagnosis may be, as these 
are conditions with opposing features (1012). In the present article, we report the coexistence of both conditions in two siblings who meet diagnostic criteria for both diseases.

\section{CASE REPORT}

\section{Case 1}

A 37-year old female patient presenting upper limb hypermobility, arthralgia in both knees since childhood and bilateral patellar chondropathy. The Brighton criteria (8) were met for BJHS: passive dorsiflexion of the fifth metacarpophalangeal joints $>90^{\circ}$, thumb opposition to forearm volar aspect (Figure 1), elbow hyperextension $>10^{\circ}$, arthralgia for more than 3 months in more than 4 joints (Table I).

At 34 years of age, after her first pregnancy, she developed arthritis in wrists and ankles, inflammatory-type back pain and buttock pain. Moreover, the symptoms worsened after her second pregnancy and the patient developed calcaneal enthesitis. She was prescribed nonsteroidal anti-inflammatory drugs (NSAIDs), with good clinical response. Physical examinations revealed wrist, ankle and sacroiliac joints painful to touch, with positive Patrick or Fabere test for bilateral sacroiliitis and 10/12 cm Schober test. Laboratory tests showed hematocrit $39.3 \%$, leucocytes $5900 / \mathrm{m}^{3}$, erythrocyte sedimentation rate (ESR) 38 $\mathrm{mm} / \mathrm{h}$, C-reactive protein (CRP) $3.75 \mathrm{mg} /$ $\mathrm{dL}$ (normal $<0.8 \mathrm{mg} / \mathrm{dL}$ ), alkaline phosphatase $42 \mathrm{U} / \mathrm{L}$, negative rheumatoid factor, positive HLA-B27, non-reactive serol-

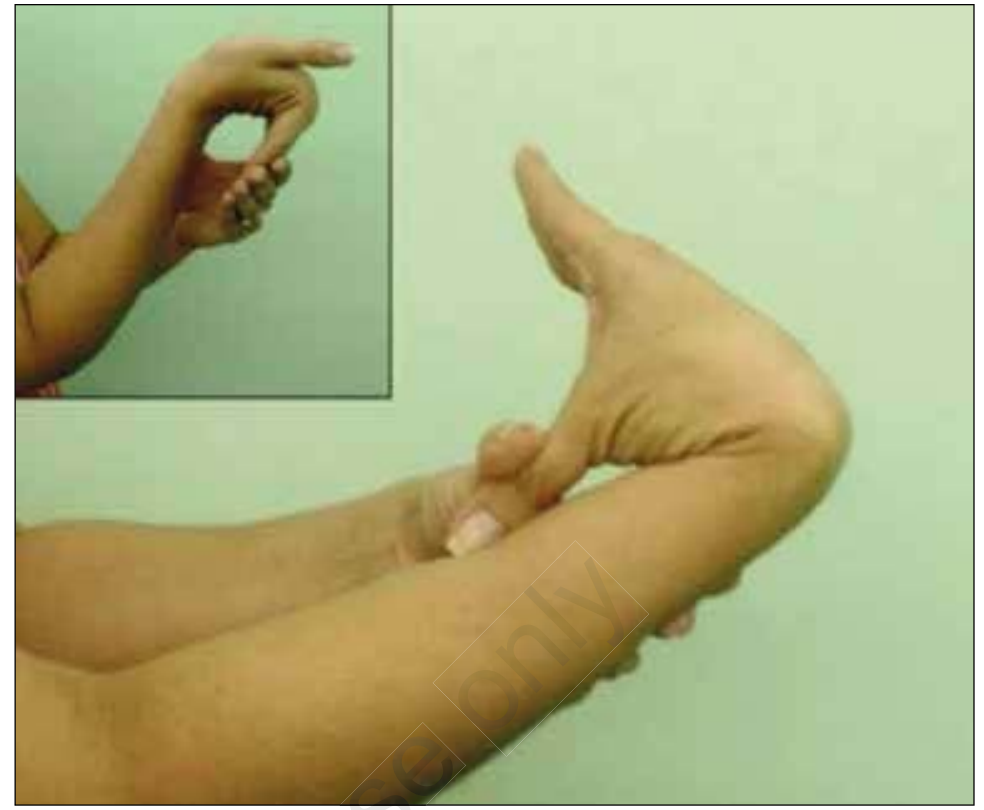

Figure 1 - Patient 1 with hypermobility in hands.

ogy for viral Hepatitis and HIV. Magnetic resonance imaging (MRI) of sacroiliac joints showed bilateral sacroiliitis with no changes in X-ray. Family history: a brother diagnosed with AS. The patient, therefore, met the ASAS criteria for nrAxSpA (13).

She was prescribed NSAIDs associated with sulfasalazine $1 \mathrm{~g} / \mathrm{day}$, and the dose was subsequently increased to 2 g/day. Treatment resulted in marked decrease of back pain, enthesitis and inflammatory parameters, but symptoms worsened after 2 years. Thus, subcutaneous $50 \mathrm{mg}$ etanercept every week was introduced, resulting in general improvement of clinical symptoms.

Table I - Several features of the two patients with both joint hypermobility syndrome and ankylosing spondylitis.

\begin{tabular}{|l|c|c|c|c|c|c|c|c|c|}
\hline Patient & Sex & Age & Symptoms & HLA-B27 & Schober's & JHS & $\begin{array}{c}\text { Family } \\
\text { history for } \\
\text { SpA }\end{array}$ & $\begin{array}{c}\text { Family } \\
\text { history for } \\
\text { JHS }\end{array}$ & $\begin{array}{c}\text { Radiographic } \\
\text { evidence of } \\
\text { sacroilitis }\end{array}$ \\
\hline Case 1 & F & 37 & $\begin{array}{c}\text { Peripheral } \\
\text { arthralgia, } \\
\text { back pain and } \\
\text { enthesitis }\end{array}$ & Yes & $12 \mathrm{~cm}$ & $\begin{array}{c}\text { Brighton score } 6 \\
\text { Arthralgia }>3 \text { months } \\
\text { in } 4 \text { or more joints }\end{array}$ & Yes & Yes & $\begin{array}{c}\text { X-ray: no } \\
\text { MRI: yes }\end{array}$ \\
\hline Case 2 & M & 30 & $\begin{array}{c}\text { Peripheral } \\
\text { arthralgia, } \\
\text { back pain and } \\
\text { enthesitis }\end{array}$ & Yes & $14 \mathrm{~cm}$ & $\begin{array}{c}\text { Ehler's Danlos } \\
\text { Brighton score } 8 \\
\text { Arthralgia }>3 \text { months } \\
\text { in 4 or more joints }\end{array}$ & Yes & Yes & $\begin{array}{c}\text { X-ray: no } \\
\text { MRI: no }\end{array}$ \\
\hline
\end{tabular}

JHS, joint hypermobility syndrome; SpA, spondyloarthritis; MRI, magnetic resonance imaging. 


\section{Case 2}

A male patient, 30 years old, presenting lax skin since his first months after birth associated with shoulder, coxofemoral and knee joint arthralgia and a feeling of joint instability, mostly in shoulders from his $7^{\text {th }}$ birthday. Arthralgia symptoms worsened during adolescence, progressing to inflammatory back pain with morning stiffness, fatigue and anxiety, exacerbated in adulthood. He was diagnosed with EDS at 24 years of age by meeting Brighton criteria (8): passive dorsiflexion of the fifth metacarpophalangeal joints $>90^{\circ}$, thumb opposition to forearm volar aspect, elbow and knee hyperextension $>10^{\circ}$ (Figure 2), arthralgia in more than 4 joints for over 3 months, $7 \mathrm{~cm}$ hyperelastic neck skin and $3 \mathrm{~cm}$ on the back of hands (Table I).

In view of persistent back pain with morning stiffness, with arthritis affecting major joints, heel pain and a family history of $\mathrm{AxSpA}$, an investigation for $\mathrm{SpA}$ was considered. Physical exam findings: painful palpation of shoulder greater tuberosity, lateral and medial epycondile, greater trochanter of femurs and bilateral insertion of the Achilles tendon, negative Patrick or Fabere test for sacroiliitis, and 10/14 cm Schober test. Laboratory test results: hematocrit $44.1 \%$, leucocytes $7200 / \mathrm{m}^{3}$, ESR 32 $\mathrm{mm} / \mathrm{h}, \mathrm{CRP} 3.1 \mathrm{mg} / \mathrm{dL}$ (normal $<0.8 \mathrm{mg} /$ dL), alkaline phosphatase $77 \mathrm{U} / \mathrm{L}$, negative rheumatoid factor, positive HLA-B27, non-reactive serology for viral hepatitis and HIV. MRI of sacroiliac joint: negative for sacroiliitis. The patient met the ASAS criteria for $\operatorname{nrAxSpA}$ (13).

Treatment was initiated with NSAIDs and sulfasalazine $1 \mathrm{~g} /$ day and the dose was subsequently increased to $2 \mathrm{~g}$ /day. Therapy resulted in significant decrease of back pain, enthesitis and inflammatory parameters after a 4-month course of treatment.

\section{DISCUSSION AND CONCLUSIONS}

The JHS is a clinical condition better understood since it was described by Kirk et al. in 1967. The most important feature of this condition is the increased range of movements, accompanied by chronic pain resulting from trauma to the joints, muscles and ligaments during daily activities, in combination with excessive joint laxity, degenerative joint disease, dislocations, joint effusions, osteoarthritis and enthesitis $(4,5,8)$.

JHS diagnosis is carried out using the 9-point Brighton score, which is based on the signs of flexibility in five body areas: dorsiflexion of the fifth metacarpophalangeal joint $\geq 90^{\circ}$; thumb opposition to forearm volar aspect, hyperextension of elbows and knees $>10^{\circ}$ and placing hands flat on the floor without bending knees. A score of 4 or greater, confirms the presence of gen-

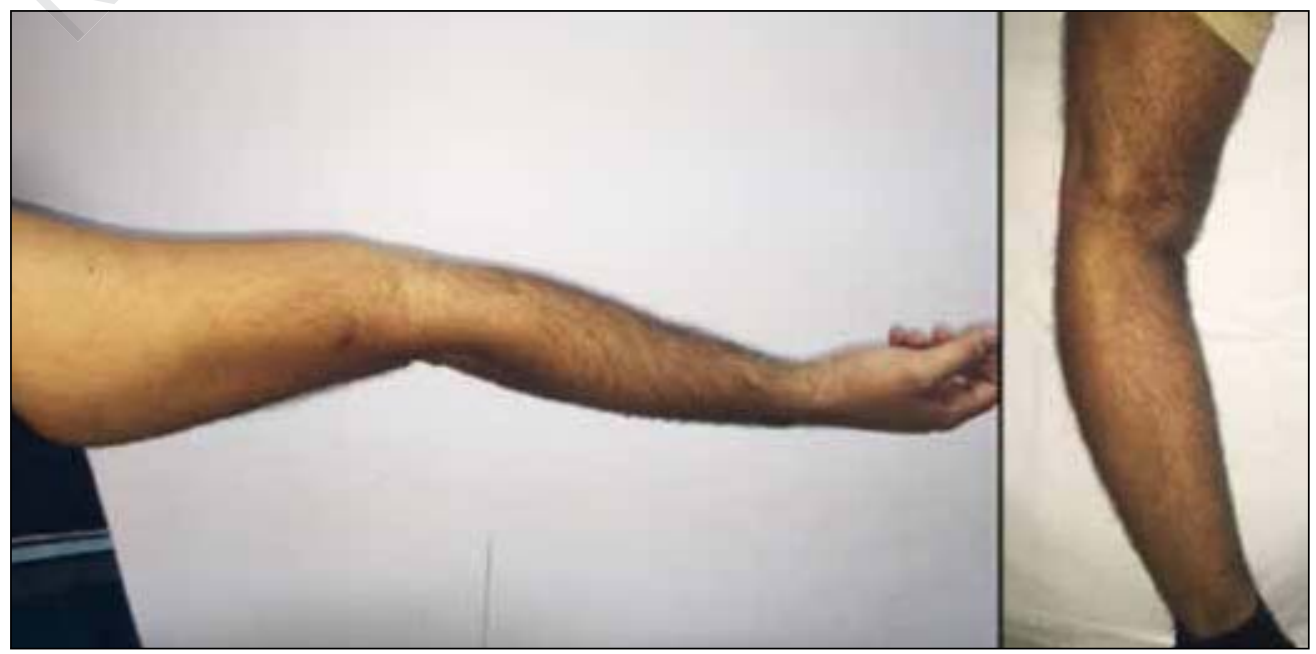

Figure 2 - Patient 2 with hypermobility in elbow and knee. 
eralized joint hypermobility and is a pre-requirement for BJHS diagnosis (6). Chronic back pain is the prevalent symptom in patients with AS and JHS and, therefore, due to their opposite effects the joint mobility criteria may be hard to define (10-12). The presence of arthritis must be ruled out in patients progressing to limited limb movement.

Spondyloarthritis and JHS are influenced by age, gender and ethnic background. Generally, the level of joint hypermobility and pain disappear with age, while SpA continues to evolve $(1,7)$. JHS is known to affect more women than men and is more prevalent among Asian and African populations as compared to Caucasians (6). Ax$\mathrm{SpA}$ affects more men than women of any ethnic background, being more frequently found in Northern Europe Caucasians and is rare among Africans $(2,14)$. In Brazil, due to marked ethnic miscegenation, the prevalence of AS in mixed race patients (mulatos) was similar to the prevalence among Caucasians, with HLA-B27 present in African Brazilians at a higher rate than in the studies with Africans (15).

HLA-B27 is highly relevant to the susceptibility to develop axial SpA, and this association was described in 1973 (3). About $95 \%$ of AS patients tested were positive for HLA-B27 and the risk of developing the disease is of approximately 5\%, being higher in patients with family history of the condition $(1,14)$.

In diseases with opposing symptoms, such as SpA and JHS, symptoms are hard to distinguish, though a similar symptom may be present, as for example, back pain and heel enthesitis (7). With the patient in case 2 we struggled with the difficulty of reaching a diagnosis as he presented inflammatory back pain with limited spinal flexion and MRI showed normal sacroiliac joint. However, considering that the patient was tested positive for HLA-B27, enthesitis and family history, he meets the classification criteria for axial $\mathrm{SpA}$ (13). In the two cases presented in this study, both patients tested positive for HLA-B27, but in just one was sacroiliitis evidenced by MRI, with no Xray changes (Table I).
It is well known that JHS patients are more prone to anxiety, depression and fatigue, which may exacerbate their joint and muscle symptoms (5), therefore some of these patients are often misdiagnosed as having fibromyalgia (FM). However, the association of those two conditions is commonly observed, suggesting that hypermobility may be a risk factor for the development of FM $(5,7)$. Notwithstanding, the presence of SpA and JHS in the same patient may cause increased emotional distress, as these patients may have suffered joint pain, myalgia, arthralgia, lax ligaments, bursitis, tendinopathies, ankyloses and osteoarthritis since an early age $(1,4)$.

The coexistence of SpA and JHS is rare and presents opposed features that can be confusing when the time comes to establish a diagnosis. We still do not know if the presence of JHS prevents SpA from progressing, or vice versa. Hence, we need to be extra cautious when diagnosing these two conditions and initiate an early treatment to prevent higher structural and emotional damage to patients.

Contributions: the authors contributed equally.

Conflict of interest: the authors declare no conflict of interest.

Informed consent: written informed consent was obtained from the patients.

\section{REFERENCES}

1. Braun J, Sieper J. Ankylosing spondylitis. Lancet. 2007; 369: 1379-90.

2. Sieper J, Poddubnyy D. Axial spondyloarthritis. Lancet. 2017 [Epub ahead of print].

3. Schlosstein L, Terasaki PI, Bluestone R, Pearson CM. High association of an HLA antigen, W27, with ankylosing spondylitis. N Engl J Med. 1973; 288: 704-6.

4. Kirk JA, Ansell BM, Bywaters EG. The hypermobility syndrome. Musculoskeletal complaints associated with generalized joint hypermobility. Ann Rheum Dis. 1967; 26: 419-25.

5. Albayrak i, Yilmaz H, Akkurt HE, et al. Is pain the only symptom in patients with benign joint hypermobility syndrome? Clin Rheumatol. 2015; 34: 1613-9. 
6. Beighton P, Solomon L, Soskolne Cl. Articular mobility in an African population. Ann Rheum Dis. 1973; 32: 413-8.

7. Fikree A, Aziz Q, Grahame R. Joint hypermobility syndrome. Rheum Dis Clin N Am. 2013; 39: 419-30.

8. Grahame R, Bird HA, Child A. The revised (Brighton 1998) criteria for the diagnosis of benign joint hypermobility syndrome (BJHS). J Rheumatol. 2000; 27: 1777-9.

9. Tinkle BT, Bird HA, Grahame R, et al. The lack of clinical distinction between the hypermobility type of Ehlers-Danlos syndrome and the joint hypermobility syndrome (a.k.a. hypermobility syndrome). Am J Med Genet A. 2009; 149A: 2368-70.

10. LeBlanc ML, Bensen WG, Goldberg WM. Hypermobility in psoriatic spondylitis. Arthritis Rheum. 1980; 23: 129-31.

11. Silva MBG, Barboza J, Carvalho M, et al. Association of ankylosing spondylitis with
Ehlers Danlos syndrome. Rev Bras Reumatol. 1989; 29: 41-2.

12. Viitanen JV. Do pathological opposites cancel each other out? Do all patients with both hypermobility and spondyloarthropathy fulfil a criterion of any disease? Scand J Rheumatol. 1999; 28: 120-2.

13. Rudwaleit M, van der Heijde D, Landewé $\mathrm{R}$, et al. The development of Assessment of Spondyloarthritis International Society classification criteria for axial spondyloarthritis (part II): Validation and final selection. Ann Rheum Dis. 2009; 68: 777-83.

14. Reveille JD, Ball EJ, Khan MA. HLA-B27 and genetic predisposing factors in spondyloarthropathies. Curr Opin Rheumatol. 2001; 13: 265-72.

15. Skare TL, Bortoluzzo AB, Gonçalves CR, et al. Ethnic influence in clinical and functional measures of Brazilian patients with spondyloarthritis. J Rheumatol. 2012; 39: 141-7. 